\title{
Investigating the Influence of Quality Factors on User Satisfaction with Summative Computer-based Assessment
}

\author{
Hassan Bello and Nor Athiyah Abdullah \\ School of Computer Sciences, Universiti Sains Malaysia, Penang, Malaysia \\ hassbell72@gmail.com \\ athiyah@usm.my
}

\begin{abstract}
Computer-based assessment or e-assessment system is an e-learning system where information communication technology is utilized for examination activity, grading, and recording of responses of the examinees. It includes the entire assessment process from the examinees, teachers, institutions, examination agencies, and the public. E-assessment systems have been used extensively in educational and non-educational settings worldwide because of their significant impact on assessment to both the institutions and students. Electronic assessment systems have many significant advantages over conventional paper-pencil-based approaches, like reducing production cost, automatic marking, and fair grading. Other benefits include the ability to conduct adaptive testing, an increase in the frequency of assessment, a large number of people could be examined, low staff requirements during the assessment, and the ability to improve the quality of the evaluation. Text, images, audio, video, and interactive virtual environments in an e-assessment system are all feasible. Nevertheless, given all these advantages, some examinees expressed negative views about electronic assessment in our study due to fear or lack of familiarity with assessment technology and lack of information on e-assessment methods. Despite the increased adoption of e-assessment in higher education and organizations, the examinees' attitudes and opinions need to be studied to implement the system successfully. In an e-assessment environment, several factors account for the evaluation of the system quality. These factors can be categorized into three dimensions: technical, educational, and economical. However, based on literature reviewed, limited studies attempted to map these quality factors to determine user satisfaction with an e-assessment system. This scarcity of e-assessment satisfaction studies is the gap the study intends to fill. Furthermore, this study's findings would help provide practical and theoretical implications for educational institutions and organizations. This study is among the first application of the Delone and McLean information system success model to predict user satisfaction with computer-based assessment in a developing, African country.
\end{abstract}

Keywords: Computer-based assessment, E-assessment, E-assessment satisfaction, Summative assessment, Computer-based test

\section{Introduction}

In recent years, an increasing number of tertiary education and examination organizations have started using electronic tools to test and evaluate students through computer-based assessment (Nardi and Ranieri, 2019). This increase is due to educational institutions' growth and the enlargement of class sizes, which led many institutions and organizations to adopt electronic evaluation tools. Likewise, the development of user-friendly web-based applications for assessments and the availability of testing protocols that are secured over the internet both led to the common utilization of online assignments, quizzes, tests, and examinations (Cassady and Gridley, 2005). Furthermore, the Covid 19 pandemic has helped to encourage a wider use of e-assessment technology, a global e-assessment application for thousands of colleges as a social distance strategy (Wafaa, Mohamed and Hossameldin, 2021). Computer-based assessment (CBA) is an electronic assessment process in which information and communication technologies (ICTs) are used for assessment activities, performance grading, and response recording. This reflects the entire assessment process from examinees, teachers, schools, examination bodies, and the general public (Hettiarachchi and Huertas, 2011).

Previous studies categorized e-assessment into summative and formative assessment (Terzis and Economides, 2011). The purpose of summative assessment is to assess whether students/learners have achieved their objectives. On the other hand formative assessments provide corrective feedback to help students achieve their goals, mostly during their learning experience (Terzis and Economides, 2011). Furthermore, various assessment approaches are used to test student's different skills using computers, including multiple-choice questions (MCQ), multiple responses, hot spots, matching, ranking, drag and drop, multiple steps, and open-ended questions (Obeidallah et al., 2015). E-assessment can be carried out with different devices, like standard desktop computers or laptops, smartphones, iPads, or through the use of electronic gaming devices (Crisp, 2011). Technically, some e-assessment designs may overcome certain challenges of paper assessments such as external support to students (Wafaa, Mohamed and Hossameldin, 2021). However, computer-based assessment systems adoption in the modern education environment still met with some challenges despite their role in solving some ISSN 1479-4403 490

CACPIL Reference this paper: Bello, H., and Abdullah, N. A., 2021. Investigating the Influence of Quality Factors on User Satisfaction with Summative Computer-based Assessment. The Electronic Journal of e-Learning, 19(6), pp. 490-503, available online at www.ejel.org 
traditional assessment problems (Al-Hakeem and Salim, 2017; Karimi, 2016). Some of the challenges include lower preference by students and exam dishonesty and misconduct (Elsalem et al., 2021), exam security and authentication (Pettit et al., 2021), digital competence lacking by the instructors (Garcia-Alberti et al., 2021) which became prominent particularly during the Covid-19 pandemic. Therefore, it is crucial to understand what overcomes user's challenges in using the system with ease and enjoyment.

The review of existing literature revealed a notable scarcity of studies, especially in a summative context, dealing with the identification of the impact of quality factors on examinees satisfaction with a computer-based assessment. Also, most of e-assessment research is concerned with finding out which factors affect student's acceptance and e-assessment adoption (Terzis and Economides, 2011; Liu, Chen, and Lu, 2015). Much research compares student's e-assessment performance with paper-based assessment (Nardi and Ranieri, 2019), while Acosta-Gonzaga and Gordillo-Mejia (2015) concentrated on the complexities of implementing the e-assessment. In the same vein, Nguyen et al (2017) deal with the e-assessment system design and security. Sanni and Mohammad (2015) studied the student's perception of e-assessment technology, while Economides (2005) concentrated on the quality requirement of the e-assessment systems. Despite these efforts, it seems that only a few studies assessed the satisfaction of students with e-assessment (Dobre, 2015; Vairamuthu and Anouncia, 2016; Bahati et al., 2019). Therefore, more studies are needed to clearly show how quality factors can be related to user satisfaction with a computer-based assessment.

In an e-assessment environment, several factors account for the system quality evaluation. Economides and Roupas (2007) categorized these factors into three dimensions: technical, educational, and economical. Economides and Roupas set out such criteria as the standard specifications for an e-assessment system. Nonetheless, minimal research maps these quality factors to determine user satisfaction with the e-assessment system. One research question guided this study: "What is the influence of quality factors on the satisfaction of the examinees with CBA?" This study identified three key quality factors in response to this question and investigated their influence on the examinee's satisfaction with CBA.

\section{Literature Review}

Three key dimensions of quality factors of computer-based testing were identified by past studies (Economides, 2005; Economides and Roupas, 2007), which include educational, economic, and technical quality dimensions. Based on these dimensions of Economides and Roupas (2007), the educational dimension comprises content, presentation, sequencing, and feedback. The technological aspect involves user interface, reliability, maintainability, performance, accessibility, networking, security, and adaptation. At the same time, cost, contract/ licensing, cost-effectiveness cover the economic aspect-basically, our study is concerned with factors that the examinees of the CBA could evaluate. Therefore, under the educational dimension, the study's criteria are the computer-based assessment contents and presentations (CBA). The cost-effectiveness of the test is our criteria under the economic factor to be determined by the examinees. Similarly, the examinee of a summative CBA could assess all the technical dimensions except maintainability, reflecting the organization's effort to maintain the CBA and make specific modifications (Economides, 2005).

Moreover, in e-assessment literature on satisfaction, few studies considered the impact of quality factors in eassessment. For instance, Vairamuthu and Anouncia (2016) showed how computer-based assessment quality factors affect usability with an online assessment in an academic institution. Likewise, Dobre (2015) addressed student satisfaction over the use of an e-assessment method using natural language processing in an intelligent tutoring system (ITS) using 27 students who have used the system in a Romanian university as respondents to a questionnaire of satisfaction. In their attempt to determine the extent to which students at the University of Rwanda are satisfied with their engagement level and the quality of their feedback from formative e-assessment, Bahati et. al. (2019) conducted an online survey with 128 respondents. They found the students are satisfied with the quality of their interaction and the quality of the strategies for formative e-assessments. The impacts of different e-assessment design on students' satisfaction were studied by Nguyen et al. (2017) on 73,373 students in the UK that have experience with 74 different e-assessment modules. They employed correlational analysis and found no significant relationship between the e-assessment design activities and student satisfaction.

Despite the findings of these studies, little is known about how the factors of quality, particularly the educational and economic factors, may contribute to the experience of the examinees for enhanced satisfaction. 


\subsection{Theoretical Framework and Research Model}

The theoretical framework of this study was based on the information system success model (ISSM) from Delone and McLean (2003) shown in Figure 1 to investigate the impact of the quality factors of e-assessment on user satisfaction. The DeLone and McLean (1992) model uses six important dimensions of IS success, namely (1) system quality, (2) information quality, (3) use, (4) user satisfaction, (5) individual impacts, and (6) organizational impact. The expanded model of Delone and McLean (2003) includes service quality as the third quality dimension, and the intention to use and net benefits as the other new dimensions. Therefore, as an adaptation of the extended model Delone and McLean (2003), this study only examines the impact of perceived quality on user satisfaction of the electronic assessment process of the Nigerian Unified Tertiary Matriculation Examination (UTME) by students from two Nigerian universities. Figure 2 shows the theoretical model for this study. The model demonstrates the relationship between perceived quality factors of e-assessment by Economides and Roupas's (2007) question content quality (educational dimension), cost-effectiveness (economic dimension), and system quality (technical dimension), and user satisfaction as the dependent variable.

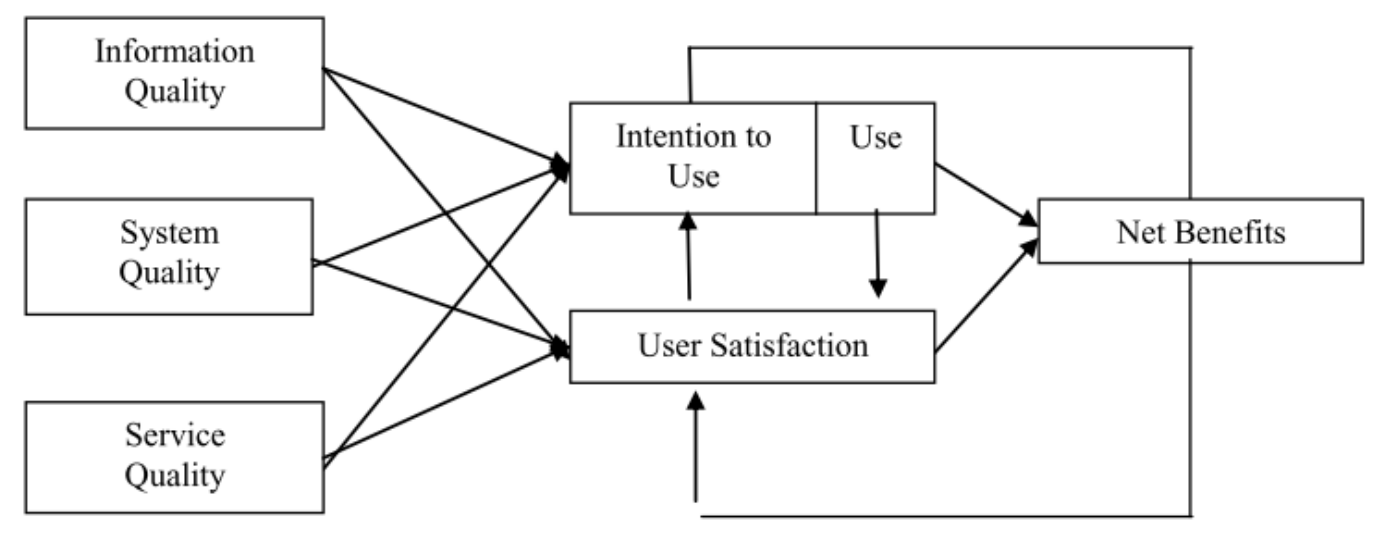

Figure 1: DeLone and McLean IS Success Model (Delone and McLean, 2003).

\subsubsection{Educational Dimension: Questions Content Quality}

The content domain is one of the educational quality dimensions proposed by Economides (2005) in evaluating the quality of e-assessment systems. The content refers to the quality and quantity of the questions in the eassessment (Economides, 2005). In addition to the questions high-quality requirements, examinees expected the questions to be valid, trustworthy, useful, up-to-date, correct, and accurate (Economides, 2005). The relevance, suitability, and appropriateness of the question to the examinees' educational level are highly important, and they should be objectively presented without discrimination concerning age, gender, religion, and political inclination (Economides, 2005). Furthermore, it is also argued that the presentation and layout of the questions in e-assessment affect the quality of the assessment ( Kuikka, Kitola and Laakso, 2014). Also, the wide acceptability of e-assessment due to Covid-19, Wafaa, Mohamed and Hossameldin (2021) established a significant difference between e-assessment questions content and paper assessment which was due to openbook nature of e-assessment.

In addition, the course content was identified in the e-learning system as a significant variable for determining the satisfaction of e-learners (Wang, 2003). In an exploratory study in Taiwan, Wang identified content as one of the dimensions in measuring e-learner satisfaction. Ideally, e-learning and e-assessment systems are supposed to be delivered with useful and sufficient content (Terzis, Moridis and Economides, 2013). Terzis and Economides (2011) defined two separate dimensions of the e-assessment content in their Computer-based Assessment Acceptance Model (CBAAM), namely: the course content and questions during e-assessment. Terzis and Economides (2011) analyzed the question content as a new construct with new items as to whether the questions were simple, clear, and comparable to the course content as measuring items and found that the question content variable also indirectly impacted the behavioral intention to use the e-assessment. Some scholars (such as Seta et al., 2018; Hassanzadeh, Kanaani, and Elahi, 2012; Mohammadi, 2015) analyzed the relationship between a specific IS quality of content and user satisfaction and found significant relationships. Seta et al. (2018), In a successful review of an e-learning system, the system information and content quality have had a significant effect on user perceived satisfaction with Indonesia's system. Similarly, Hassanzadeh, 
Kanaani, and Elahi (2012) and Mohammadi (2015) found a significant influence of content quality on user satisfaction with the e-learning program in their separate studies to assess e-learning success in Iran.

However, in some studies, the content has had an insignificant impact on the satisfaction of users. In a work to evaluate the effectiveness of e-training in Malaysian multinationals, Ramayah, Ahmad, and Hong (2012) found the training contents have insignificant impacts on users' satisfaction. But, limited studies exist that associate questions content quality of e-assessment and examinee's satisfaction. Therefore, it is vital to test the relationship between questions content quality and user satisfaction. Thus, this study hypothesized the following:

H1: Questions content quality of an e-assessment positively influences examinee satisfaction with the eassessment.

\subsubsection{Economic Dimension: E-assessment Cost-effectiveness}

In e-learning, cost-effectiveness is regarded as an advantage of e-learning for learners (Shee and Wang, 2008). Cost-effectiveness is one of the economic dimensions in evaluating e-assessment as proposed by Economides and Roupas (2007). The cost-effectiveness in this context is referring to whether e-assessment can provide a better quality of service (especially with the involvement of third parties in the provision of e-assessment services and facilities) than the paper-based exam, relative to the cost of using the e-assessment and paperbased; and how this will affect the overall satisfaction of the examination experience. Ideally, the examinees should be aware of the various costs, and the payments should be transparent at any time (Economides, 2005). The flexibility, duration, visibility, discounts (e.g., concerning the number of tests, examinees), and guarantees are also important parameters. Our study focuses on cost-effectiveness as an antecedent of user satisfaction rather than cost. Cost-effectiveness in computing refers to the degree to which a computer resource's benefit is worth the price invested (Saya, Pee, and Kankanhalli, 2010). In e-banking services, it was established that costeffectiveness is one factor determining customer satisfaction in India (Kumbhar, 2011a).

The cost-effectiveness of this study is a key variable given the peculiarity of e-assessment fees in Nigeria. Since the introduction of e-assessment by the Joint Admission and Matriculation Board (JAMB) in 2013, there were many protests and calls on the examining body to reduce the price of the examination. As reported on $3^{\text {rd }}$ March 2016 by one of the Nigerian dailies, AllAfrica, on a bill, the Senate passed, which is yet to be implemented

The Senate yesterday cut the registration fees for the Unified Tertiary Matriculation Examinations (UTME) to N2, 500 from the initial cost of N5, 560. The decision followed the adoption of the report of the Senate committee on tertiary institutions on the inquiry into the new admission policy of the Joint Admission and Matriculation Board (JAMB)

In the same vein, there were calls to extend the expiration time of the examination to three years all because of the fees as also reported by the Premium Times a Nigerian newspaper on $3^{\text {rd }}$ March 2016

The Senate has said the application fee payable to Joint Admissions and Matriculation Board, JAMB, the examination should not exceed N2, 500. While the Senate said the application fee should not exceed $\mathrm{N} 2,500$, it said course forms and all other incidental activities around the examination should be free. The legislative body also extended JAMB's entrance examination validity period to three years from one year

There are few studies on the relationship between the cost-effectiveness of examination and user satisfaction. Therefore, these relationships need to be examined to ensure the relationship between exam cost-effectiveness and user satisfaction within the e-assessment experience. Hence we propose the following hypothesis: H2: E-assessment cost-effectiveness positively influences examinee's satisfaction

\subsubsection{Technical Dimension: System Quality}

System quality or technical system quality is primarily concern with measuring performance characteristics of the information system in question. According to DeLone and McLean (1992), system quality of information systems is more oriented toward the technical performance of the system. Determining a sound quality system will create an easy-to-use environment in which users will skillfully discover practical IS groups and navigate efficiently the materials provided by the IS (Cheng, 2012). Gorla, Somers and Wong (2010) described system quality as the IS's processing power and its data components, which make the system technically sound. In their 
view Freeze et al. (2010) referred to system quality as the individual perception of system output. In other words, the quality of the system is measured in terms of both the user's hardware and the particular software applications built for their intended use and needs.

For this study, system quality is defined as one of the e-assessment quality factors that primarily concern systemrelated and task-related features such as reliability, flexibility (Flexible to easily make changes), integration, response time, security, ease of use, ease of learning, user requirements, system features, system accuracy, sophistication, and customization (DeLone and McLean, 2003). Several researchers emphasized that system quality and user satisfaction were significantly related (e.g., Delone and McLean, 2003; Fang, Chiu, and Wang, 2011; Ramayah and Lee, 2012; Al-Mamary et al., 2015; Seta et al., 2018; Masrek and Gaskin, 2016; Al-Fraihat et al., 2020). Delone and McLean (2003) theorized the quality of the system as one of the fundamental determinants of an individual's satisfaction. In their efforts to model the repurchase intentions of customers in the context of online shopping, Fang, Chiu, and Wang (2011) confirmed that system quality has a major impact on customer satisfaction. Similarly, Ramayah and Lee (2012) noted that system quality has an important positive relationship to the e-learning system's user satisfaction. Also, this was supported by Almarashdeh (2016) in a study assessing teachers' satisfaction with the e-learning system inside a distance learning program. Similar findings were reported by Hadji and Degoulet (2016) with the clinical information system (CIS) and Mohammadi (2015), Hammouri and Abu-Shanab (2018), Hassanzadeh, Kanaani, and Elahi (2012), Navimipour and Zareie (2015) with e-learning systems.

Researchers (such as Chatzoglou, Fragidis, and Aggelidis, 2012) have however, found system quality to influence user satisfaction through information quality indirectly. System quality has also been found to have an insignificant effect on learning management system (LMS) user satisfaction in Nigeria (Yakubu and Dasuk, 2018). Therefore, it is important to test the relationship between the e-assessment system's quality and the examinee's satisfaction based on the literature discussed. The following hypothesis is based on that:

H3: System Quality will positively influence examinee satisfaction with e-assessment.

The constructs adopted from the Delone and McLean (2003) model are system quality and satisfaction. Also worthy of mentioning, our model does not include the "use" construct together with the remaining construct of "net benefits" due to the following reasons: (1) our scope is to measure user satisfaction with the system not to measure the outcomes of the user satisfaction (2) In a mandatory system setting, use does not make sense regarding the system evaluation (Petter, DeLone, and McLean, 2008; Sedera and Gable, 2004; Delone and McLean, 2003). (3) Some researchers argued regarding the consideration of use because many studies (such as Al-Fraihat et al., 2020) found the relation between quality factors and use not supportive. (4) researchers like Seddon (1997) argued that use is a behavior, not an effective measure. Similarly, Ramayah, Nejati, and Shafaei (2015) and Cheng (2012) replaced information quality dimension of Delone and McLean (2003) with content quality on the ground that in information system with personal content-oriented (like e-assessment, e-learning, web blogs) information quality can be replaced with content quality. Therefore, the information quality construct is replaced with questions content quality in our study. Similarly, in this study, the construct of service quality is not considered because it was not a quality dimension of Economides and Roupas (2007) e-assessment quality factors and also some studies like Hammouri and Abu-Shanab (2018) excluded it in their study of exploring factors affecting e-learner satisfaction with learning management system. 


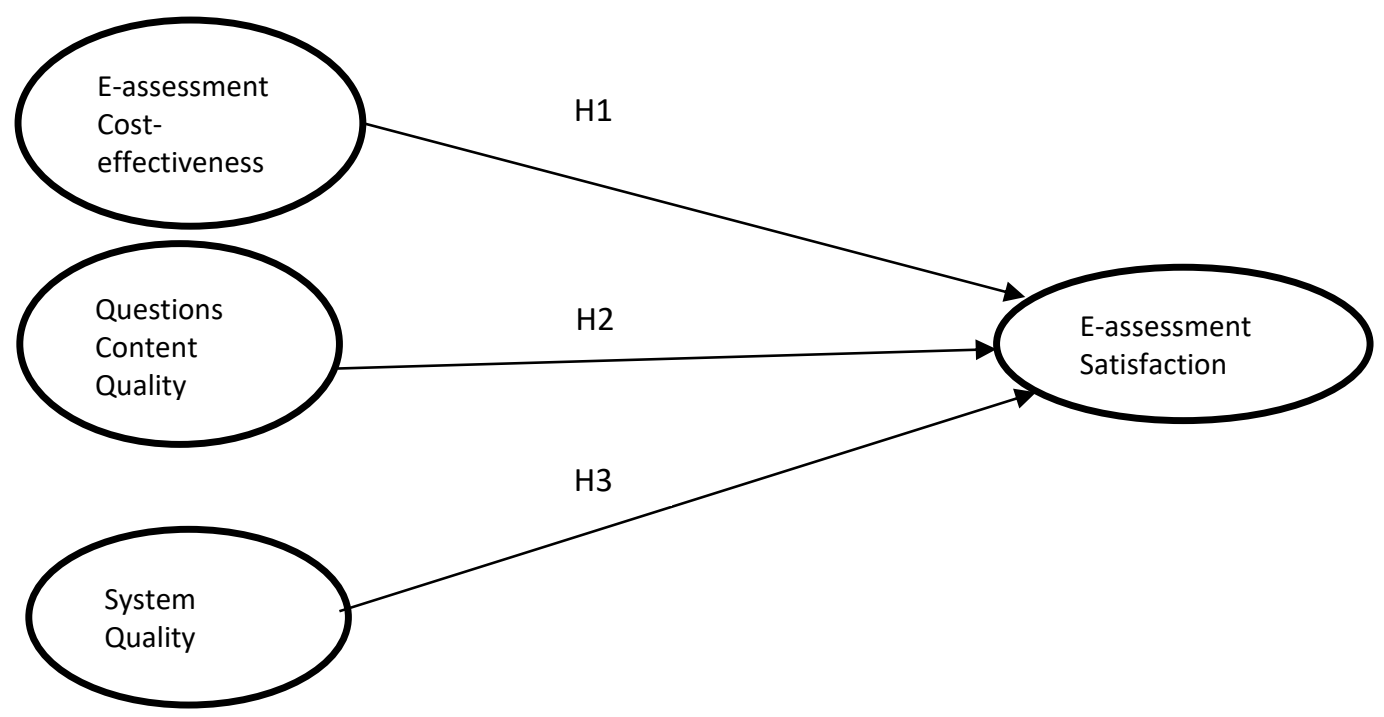

Figure 2: Research Model

\section{Methodology}

\subsection{Research Participants and Data Collection}

The selection of a quantitative approach to this study is based on the abundance of empirical studies rooted in the Delone and Mclean model, which is the theoretical framework of this study. This cross-sectional study maps quality factors measures of computer-based assessment to examinee's satisfaction. It tests the effect of these quality factors (exam cost-effectiveness, questions content quality, and system or technical quality) in determining examinee's satisfaction with CBA. According to the reviewed literature, the constructs and measures used in this study have rarely before been used to predict user satisfaction with CBA.

This study's population is students from Nigerian higher education institutions who used the computer-based unified tertiary matriculation exam (UTME) to gain admission between 2015-2019. However, the target sample for the study were undergraduates of two public universities in the state of Kano, Nigeria, that have used the unified tertiary matriculation examination (UTME) computer-based test to secure admission into the universities between the period 2015-2019. The reason for choosing undergraduates from these two universities was because of their familiarity and experience with the UTME e-assessment system, which can clarify their views of e-assessment in adequate detail. They also comprised the research convenience sample. Data were collected over a week, with the help of two research assistants, through a survey from these universities. A total of 300 potential respondents have been approached and asked to join the study. 229 replied by returning the questionnaire (a remarkable response rate of 76.3 percent), which is more than the minimum number of samples needed using the Gpower 3.1 software (Faul et al , 2009) setting of 119 samples.

A questionnaire was developed based on existing and relevant instruments from the literature. The questionnaire consisted of 23 objects, which were split into two parts. The first section consisted of six items which asked for demographic data (e.g., gender, age, school type, e-assessment experience, e-assessment training participation). The second part asked about quality assessment and satisfaction by the examinee and consist of seventeen items. Items for measuring the quality assessment and the examinee's satisfaction were adopted from the literature. Three items on exam cost-effectiveness were adopted from Kim, Yoon, and Han (2016) to assess the overall price, current price, and cost-effectiveness; three items on questions content quality were adopted from Nikou and Economides (2017) to measure question understandability, relevance, and usefulness; while five items adapted from Holsapple and Lee-Post (2006) on system quality were used to measure the e-assessment in terms of system's user-friendliness, stability, security, speed, and response; and six items were used to measure the satisfaction of the examinee with the e-assessment taken from Mohammadi (2015) to assess user's evaluation on his satisfaction in using the system.

The issues of common method bias ( $\mathrm{CMB}$ ) were addressed by adopting some procedural strategies to minimize them as follows: Firstly, a cover sheet and a set of instructions accompanied the questionnaire so that the respondents will be motivated by knowing how the information will be used or how it will benefit them or the 
society at large. Secondly, we removed common scale property by adopting 5-point Likert and 7-point Likert scales, which, according to Jordan and Troth (2020), common scale property increases common method biases.

Table 1 details the respondents' demographics. Most respondents were students of science because one of the universities is a university of science and technology.

Table 1: Demographic information of the Respondents

\begin{tabular}{lcl}
\hline & Frequency & Percentage \\
\hline Age & & \\
$16-20$ years & 95 & $41.5 \%$ \\
$21-25$ years & 89 & $38.9 \%$ \\
$26-30$ years & 36 & $15.7 \%$ \\
$31+$ years & 9 & $3.9 \%$ \\
\hline Gender & & \\
Male & 148 & $64.6 \%$ \\
Female & 81 & $35.4 \%$ \\
\hline Type of Secondary School & & \\
Public & 109 & $47.6 \%$ \\
Private & 120 & $52.4 \%$ \\
\hline Course & & \\
Science & 158 & $69 \%$ \\
Art & 47 & $20.5 \%$ \\
Others & 24 & $10.5 \%$ \\
\hline
\end{tabular}

\section{Data analysis and Results}

For the model analysis, the structural equation modelling (SEM) approach was adopted. SmartPLS3 (Ringle, Wende, and Becker, 2015) software package was used to analyze the collected data as it is considered a complete statistical procedure that allows the research model to be evaluated and updated simultaneously, including the relationships between latent variables. The first step is to test the measurement model by examining the variable's reliability, convergent, and discriminant validities. The second stage is related to the structural model evaluation by exploring the structural model's paths and checking the significance of the relationships between the constructs.

\subsection{Measurement Model}

According to Hair et al. (2017), to assess the measurement model, a study needs to report the indicator loadings, average variance extracted (AVE), composite reliability (CR), and also the discriminant validity. Reliability or internal consistency reliability of a construct reflects the indicators consistency in measuring a given construct ( Chen, Chen and Chen, 2009). According to Hair et al. (2017), if composite reliability (CR) is greater than 0.7, the scale can be regarded as being highly reliable. As can be seen in Table 2, reliability for all constructs exceeded 0.7, meeting the reliability criterion for research tools. Similarly, the reliability of indicators (outer loadings) indicates the degree to which an indicator or group of indicators is consistent with what it aims to measure (Urbach and Ahlemann, 2010). We adopted Byrne's (2016) suggestion, where loading values equal to and above 0.5 are acceptable when the summation of the loads results in high loading scores, the Average Variance Extracted (AVE) scores greater than 0.5 are acceptable. Similarly, a construct's convergent validity represents the degree to which different indicators are used to measure the same construct and strongly correlate the different indicator scores (Chen, Chen and Chen , 2009). We use the extracted average variance (AVE) to validate the convergent validity as suggested by Hair et al. (2017) appropriate value of AVE > 0.50 is recommended, indicating that the construct score includes more than half the indicator variance. The indicator loads, $C R$, and AVE for the reflectively measured constructs are shown in Table 2.

Table 2: Measurements Model

\begin{tabular}{lllll}
\hline Constructs & Items & Loadings & CR & AVE \\
\hline Exam cost-effectiveness & CEF1 & 0.786 & 0.845 & 0.646 \\
& CEF2 & 0.885 & & \\
& CEF3 & 0.733 & & \\
Questions Content Quality & QCQ1 & 0.779 & 0.851 & 0.655 \\
& QCQ2 & 0.838 & &
\end{tabular}




\begin{tabular}{lllll}
\hline Constructs & Items & Loadings & CR & AVE \\
\hline \multirow{3}{*}{ E-assessment Satisfaction } & QCQ3 & 0.811 & & \\
& SAT1 & 0.633 & 0.908 & 0.625 \\
& SAT2 & 0.741 & & \\
SAT3 & 0.790 & & \\
SAT4 & 0.859 & & \\
System Quality & SAT5 & 0.879 & & \\
& SAT6 & 0.815 & & \\
& SYQ1 & 0.801 & 0.851 & \\
& SYQ2 & 0.815 & & \\
SYQ3 & 0.582 & & \\
& SYQ4 & 0.710 & & \\
SYQ5 & 0.799 & & \\
\hline
\end{tabular}

Note: CR is Composite Reliability, and AVE is Average Variance Extracted

The next step of the measurement model evaluation is the discriminant validity (DV) assessment. Discriminant validity implies the degree to which a construct differs from other constructs within the model. This will be verified by comparing the square root of the Average Variance Extracted (AVE) with the correlations among constructs. If higher than the correlation values are the square roots of the AVE values in the respective row and column, it is verified that the measurements are discriminant. Table 3 shows the square roots of the AVEs greater than the row and column values. Therefore the Discriminant Validity is confirmed.

Table 3: Discriminant Validity

\begin{tabular}{llllll}
\hline & & $\mathbf{1}$ & $\mathbf{2}$ & $\mathbf{3}$ & $\mathbf{4}$ \\
\hline 1 & E-assessment Satisfaction & 0.791 & & & \\
2 & Exam cost-effectiveness & 0.472 & 0.804 & & \\
3 & Questions Content Quality & 0.613 & 0.389 & 0.810 & \\
4 & System Quality & 0.606 & 0.447 & 0.612 & 0.746 \\
\hline
\end{tabular}

\subsection{Structural Model}

The structural model was used to test the relationships among variables adopted in this study's model. The path coefficients $(\beta)$ were calculated in conjunction with their degree of significance for estimating construct effects. A bootstrapping method of 5,000 samples was used to determine the level of significance of the paths (t-value). So, we examine the model's paths to test the study's three hypotheses. Table 4 presents the results of analyzing the path.

Table 4: Hypothesis testing

\begin{tabular}{|l|l|l|l|l|l|}
\hline & Relationship & Std. Beta & Std. Error & t-value & Decision \\
\hline H1 & Exam cost-effectiveness -> E-assessment Satisfaction & 0.200 & 0.055 & $3.641^{* * *}$ & Supported \\
\hline & $\begin{array}{l}\text { Questions Content Quality -> E-assessment } \\
\text { H2 }\end{array}$ & Satisfaction & 0.350 & 0.079 & \\
\hline H3 & System Quality -> E-assessment Satisfaction & 0.302 & 0.083 & $3.608^{* * *}$ & Supported \\
\hline${ }^{* * *} \mathrm{P}<.01$
\end{tabular}

The independent variables of exam cost-effectiveness $(\beta=0.200, p<0.01)$, questions content quality $(\beta=0.350$, $p<0.01)$, and system quality $(\beta=0.302, p<0.01)$ were found to be positively related to the satisfaction of the examinee and collectively explained the variance of $49.2 \%$ in satisfaction with the summative e-assessment. Therefore, support was provided for $\mathrm{H} 1, \mathrm{H} 2$, and $\mathrm{H} 3$, as shown in Figure 3. 


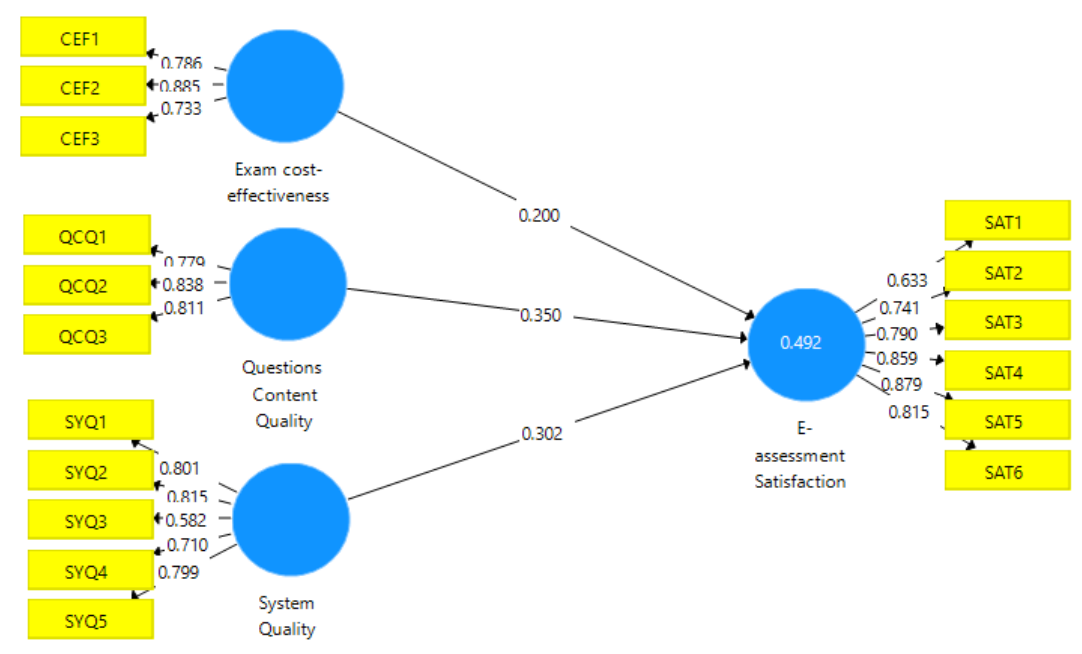

Figure 3: Hypotheses testing results

As suggested by Hair, Ringle and Sarstedt (2013), we also used a blindfolding procedure with a distance value of 10 to calculate the Q2 or predictive relevance. According to Hair, Ringle and Sarstedt (2013), blindfolding is a measure based on a sample reuse methodology, omits part of the data matrix, estimates the parameters of the model, and predicts the portion omitted using estimates ( Hair, Ringle and Sarstedt, 2013). User satisfaction is greater than 0 with a Q2 value of 0.288 and only one endogenous construct (Fornell and Larcker, 1981), so we should recognize the model as having the modest predictive capacity (Hair et al., 2017).

\section{Discussion and Conclusions}

The success of an electronic assessment system in academic institutions can be attributed to the examinee experience and satisfaction. This study, therefore, examined the effect of e-assessment quality factors on the satisfaction of examinees for the matriculation examination. There is an increase in challenges faced by the examinees of electronic tests in Nigeria, particularly those of UTME CBT (Sanni and Mohammad, 2015), which have a potential threat to achieving the ultimate success of the system. Furthermore, there are few studies investigating examinees' objective and subjective assessment of the system by employing a well-established information system theory, particularly within the context of developing countries such as Nigeria. This study aims to fill these gaps using the updated information system success model from Delone and McLean (2003) to examine quality factors role in assessing user satisfaction with a computer-based assessment.

The study findings showed that the model dimensions explain $49 \%$ of examinee satisfaction with e-assessment in Nigeria, which is considered to have a moderate impact in IS studies (Knowles, Hyde and White, 2012). According to the Smart PLS parameters, all the determinants of user satisfaction proposed in the study model are significant. This result is in line with previous studies where a modified Delone and McLean (2003) model has been used to predict user satisfaction (e.g., Ramayah and Lee, 2012). Literature reviewed showed only one study in the field of computer-based assessment utilized Delone and McLean (2003) model to evaluate the usability of an online-based assessment system (Vairamuthu and Anouncia, 2016). The current study strengthens the predictive power of modified Delone and McLean (2003), which can be employed further to investigate examinee satisfaction.

The cost-effectiveness of the e-assessment system significantly influences the satisfaction of the examinees. This is in-line with previous studies (e.g., Kumbhar, 2011b) and has implications for Nigerian legislators who are striving to enact a bill (yet to be approved by the executives) mandating the JAMB to reduce the cost of the UTME examination or extend the expiration period of the examination result (the daily). For instance, the registration fee for the examination, the training fee, the mock exam fee should be harmonized and paid collectively during registration because some examinees were not aware of the other fees being charged during 
training and mock examination. The cost-effectiveness is thus related to the examinee satisfaction with respect to the fees and costs.

The quality of the exam questions (content, presentation) was found to significantly predict the examinee satisfaction with the summative e-assessment. The result showed a moderately strong relationship between the two variables. They indicated the importance of the question content quality while predicting the determinants of summative e-assessment satisfaction in a Nigerian context. The questions should be accurate without errors and specific (relevant to the course chosen and the right combination chosen by the examinee), appropriate and fair considering the examinee age and educational background. The assessment (exam) questions should be comprehensive and complete, covering all the main ideas and key points. This result is consistent with the findings of Seta et al. (2018), Hassanzadeh, Kanaani an Elahi (2012), and Mohammadi (2015) that found a significant effect of content quality of e-learning on user satisfaction.

The system quality, which is technical quality dimensions, influences user satisfaction with summative eassessment. The system quality element of system security was found to be the test taker's most significant concern, with an average of 4.02 on a scale of 5.0, followed by the system speed due to the value of time in an assessment process. The examinees are mostly concerned about how secure the system is in securing their information and results. These findings support the conclusion made by Ramayah and Lee (2012), and AlMamary et al. (2015) and other previous ones (e.g., Seta et al., 2018; Al-Fraihat et al., 2020) on how the quality of the system shows strong effects on the user satisfaction.

\section{Implications}

This study found some quality factors to be more satisfying for e-assessment systems. The findings have several implications for educational institutions and exam organizations operating in Nigeria and other developing countries. Some institutions and organizations are trying hard to establish a valid and trustworthy examination; many adopted an electronic assessment system. These institutions and organizations need to subsidize the rate of the examination fees so that the examinees should be aware of the various costs, and the payments should be transparent at any time.

The results revealed that the strongest predictor of satisfaction with e-assessment was the quality of question content. The higher the quality of the e-assessment questions we expect, the more likely the examinees are satisfied with the assessment process. The quality of the questions should be understandable, sufficient, and covered all the intended topics. It should be balanced in terms of difficulty levels, skills, and ability to be tested. The questions should be easy, timely, and cost-efficient (to the institutions and organizations) to develop, manage, validate, and update. The authors of the question items (instructors, lecturers, and examiners) should possess the required credentials and reputes in their respective subjects and courses. The questions should be based on a range of media (like text, image, video, audio) of higher quality, and the experience with the system should be enjoyable (Economides, 2005).

Technically, the result also revealed the importance of system quality for predicting examinee satisfaction. Therefore, this calls for a serious implication for the system designers, developers, technical staff, examination center managers to provide a highly secured system, a very fast, user-friendly, and stable system, mainly through the provision of a steady power supply during the examination ( Sanni and Mohammad, 2015).

\section{Limitations and Recommendations for Future Research}

Although this study is quantitative, it may still affect some limitations on the overall generalization of the research findings. Since this survey captured targeted respondent responses (i.e., through non-random sampling) in the study context, the results may not be generalized to other e-assessment systems. Additional research is required to confirm the findings in various e-assessment systems in the country. While this study employed some strategies to overcome $\mathrm{CMB}$, applying this model in other e-assessment systems can further establish the hypothesized direct relationships. Also, the quality of service was not taken into account in this study, although some examination services, personnel, and facilities are provided by third parties involved in conducting the assessment, like examination centres, technical staff, computer systems, and other infrastructures. 
Furthermore, the cross-sectional nature of data collection is another limitation of this analysis, thereby restricting the possibility of detecting particular examinee changes over a certain period. In addition, instead of collecting data from students from different universities across the country, this study only covered students enrolled in just two universities. This, therefore, calls for more cross-regional studies to investigate the satisfaction of the examinees with UTME e-assessment.

Based on these limitations, future studies should consider other quality factors such as service quality, especially when conducting e-assessment involving third parties. Subsequent studies may also suggest a longitudinal study approach to increase the likelihood of causal inferences regarding e-assessment satisfaction among the examinees. The relationships among the construct in this model represent a linear relationship. Although the study's aim is attained in the country context of Nigeria, future studies are required to integrate the mediating or moderating effects of other relevant variables. For example, technology readiness is an essential variable in influencing user satisfaction ( Wang, So and Sparks, 2017). We recommend using other techniques and methods to evaluate user satisfaction with CBA since the analysis used a data collection survey method.

\section{References}

Acosta-Gonzaga, E. and Gordillo-Mejia, A., 2015. Technology-enhanced assessment process: issues affecting e-assessment uptake. ECORFAN Journal-Mexico, 6(15), pp. 1236-1253.

Al-Fraihat, D., Joy, M., Masa'deh, R., and Sinclair, J., 2020. Evaluating e-learning systems success: an empirical study. Computers in Human Behaviour, 102 (2020), pp. 67-86.

Al-Hakeem, M. S. and Salim, A., 2017. Developing a new e-exam platform to enhance the university academic examinations: the case of Lebanese French university. International Journal of Modern Education and Computer Science, 9(5), pp. 9-16.

Al-Mamary, Y. H., Shamsuddin, A., Abdul Hamid,N., and Al-Maamari, M.H., 2015. Adoption of management information systems in context of yemeni organizations: A structural equation modeling approach. Journal of Digital Information Management, 13(6), pp. 429-444.

Almarashdeh, I., 2016. Sharing instructors experience of learning management system: A technology perspective of user satisfaction in distance learning course. Computers in Human Behavior, 63 (2016), pp. 249-255.

Bahati, B., Fors, U., Hansen, P., Nouri, J. and Mukama, E., 2019. Measuring learner satisfaction with formative e-assessment strategies. International Journal of Emerging Technologies in Learning, 14(7), pp. 61-79.

Byrne, B. M., 2016. Structural equation modeling with AMOS: Basic concepts, application, and programming. $2^{\text {nd }}$ ed. New York: Routledge.

Cassady, J. C. and Gridley, B. E., 2005. The effects of online formative and summative assessment on test anxiety and performance. The Journal of Technology, Learning and Assessment, 4(1), pp. 4-30.

Chatzoglou, P. D., Fragidis, L. L. and Aggelidis, V., 2012. Hospital information system Evaluation. In: $10^{\text {th }}$ International Conference on Information Communication Technologies in Health. Samos Island Greece, 12-14 July 2012 doi: 10.11239/jsmbe1963.20.378.

Chen, S. C., Chen, H. H. and Chen, M. F., 2009. Determinants of satisfaction and continuance intention towards self-service technologies. Industrial Management and Data Systems, 109(9), pp. 1248-1263.

Cheng, Y. M., 2012. Effects of quality antecedents on e-learning acceptance. Internet Research, 22(3), pp. 361- 390.

Crisp, G., 2011. Teacher' s handbook on e-assessment. transforming assessment-An ALTC Fellowship Activity,18, p. 24. Available at: http://transformingassessment.com/sites/default/files/files/Handbook for teachers.pdf. [Accessed 14 May 2021].

DeLone, W. H. and McLean, E. R., 1992. Information systems success: the quest for the dependent variable. Information Systems Research, 3(1), pp. 60-95.

Delone, W. and McLean, E., 2003. The Delone and Mclean model of information systems success: A ten-year update. Journal of Management Information Systems, 19(4), pp. 9-30.

Dobre, I., 2015. Students' satisfaction analysis related to an e-assessment system that uses natural language processing. In: The 11th International Scientific Conference eLearning and Software for Education. Bucharest, 23-24 April 2015. doi: 10.12753/2066-026X-13-131.

Economides, A. A., 2005. Computer adaptive testing quality requirements. In: World Conference on E-Learning in Corporate, Government, Healthcare, and Higher Education, Vancouver, Canada. 24-28 October 2005, Association for the Advancement of Computing in Education.

Economides, A. A. and Roupas, C., 2007. Evaluation of computer adaptive testing systems. International Journal of WebBased Learning and Teaching Technologies (IJWLTT), 2(1), pp. 70-87.

Elsalem, L., Al-Azzam, N., Jum'ah, A. A., andObeidat, N., 2021. Remote e-exams during covid-19 pandemic : a crosssectional study of students ' preferences and academic dishonesty in faculties of medical sciences. Annals of Medicine and Surgery, 62(2021), pp 326-333.

Fang, Y. H., Chiu, C. M. and Wang, E. T. G., 2011. Understanding customers' satisfaction and repurchase intentions: an integration of IS success model, trust, and justice. Internet Research, 21(4), pp. 479-503. 
Faul, F., Erdfelder, E., Buchner, A,. and Lang, A., 2009. Statistical power analyses using G*Power 3.1: tests for correlation and regression analyses. Behavior Research Methods, 41(4), pp. 1149-1160.

Fornell, C., and Larcker F. D. 1981. Evaluating structural equation models with unobservable variables and measurement error. Journal of Marketing Research, 18(1), pp. 39-50.

Freeze, R. D., Alshare, K. A., Lane, P.L., and Wen, J. H., 2010. IS success model in e-learning context based on students' perceptions. Journal of Information Systems Education, 21(2), pp. 173-183.

Garcia-Alberti, M., Suarez, F., Chiyon, I. and Feijoo, J.C.M., 2021, Challenges and experiences of online evaluation incourses of civil engineering during the lockdown learning due to the covid-19 pandemic. Education Sciences 11(59), pp 1-19.

Gorla, N., Somers, T. M. and Wong, B., 2010. Organizational impact of system quality, information quality, and service quality. Journal of Strategic Information Systems. 19(3), pp. 207-228.

Hadji, B. and Degoulet, P., 2016. Information system end-user satisfaction and continuance intention: A unified modeling approach. Journal of Biomedical Informatics, 61, pp. 185-193.

Hair, Jr., J.F., Matthews, L.M., Matthews, R.L. and Sarstedt, M., 2017. Pls-sem or cb-sem: updated guidelines on which method to use. International Journal of Multivariate Data Analysis, 1(2), pp. 107-123.

Hair, J. F., Ringle, C. M. and Sarstedt, M., 2013. Partial least squares structural equation modeling: rigorous applications, better results and higher acceptance. Long Range Planning, 46(1-2), pp. 1-12.

Hammouri, Q. and Abu-Shanab, E., 2018. Exploring factors affecting users' satisfaction toward e-learning systems. International Journal of Information and Communication Technology Education, 14(1), pp. 44-57.

Hassanzadeh, A., Kanaani, F. and Elahi, S., 2012. A model for measuring e-learning systems success in universities. Expert Systems with Applications, 39(12), pp. 10959-10966.

Hettiarachchi, E. and Huertas, M., 2011. E-assessments and how it can be adapted to mathematical e-learning. Journal on Mathematical E-Learning (E-MATH). [e-journal] Available at:

https://www.academia.edu/download/17173069/22 emath e-assessments an mathematical elearning.rtf.pdf[Accessed 23 May 2020].

Holsapple, C. W. and Lee-Post, A., 2006. Defining, assessing, and promoting e-Learning Success: an information systems perspective. Decision Sciences Journal of Innovative Education, 4(1), pp. 67-85.

Jordan, P. J. and Troth, A. C., 2020. Common method bias in applied settings: The dilemma of researching in organizations. Australian Journal of Management, 45(1), pp. 3-14.

Karimi, S. 2016., Do learners ' characteristics matter? an exploration of mobile-learning adoption in self-directed learning. Computers in Human Behavior, 63 pp. 769-776.

Kim, S. C., Yoon, D. and Han, E. K., 2016. Antecedents of mobile app usage among smartphone users. Journal of Marketing Communications, 22(6), pp. 653-670.

Knowles, S. R., Hyde, M. K. and White, K. M., 2012. Predictors of young people's charitable intentions to donate Money: An extended theory of planned behavior perspective. Journal of Applied Social Psychology,42(9), pp. 2096-2110.

Kuikka, M. Kitola, M. and Laakso, M. J., 2014. Challenges when introducing electronic exam. Research in Learning Technology, [e-journal] 22(22817) pp. 1-17. doi: 10.3402/rlt.v22.22817.

Kumbhar, V., .2011a. Factors affecting on customers' satisfaction an empirical investigation of ATM service. International Journal of Business Economics and Management Research, 2(3), pp. 144-156.

Kumbhar, V. M., 2011b, Factors affecting the customer satisfaction in e-banking: some evidence from Indian banks. Management Research and Practice, 3(4), pp. 1-14.

Liu, I. F., Chen, R. S. and Lu, H. C., 2015. An exploration into improving examinees' acceptance of participation in an online exam. Educational Technology and Society, 18(2), pp. 153-165.

Masrek, M. N. and Gaskin, J. E., 2016. Assessing users satisfaction with web digital library: the case of Universiti Teknologi MARA. International Journal of Information and Learning Technology, 33(1), pp. 36-56.

Mohammadi, H., 2015. Investigating users' perspectives on e-learning: an integration of TAM and IS success model. Telematics and Informatics, 32(4), pp. 701-719.

Nardi, A. and Ranieri, M., 2019. Comparing paper-based and electronic multiple-choice examinations with personal devices: Impact on students' performance, self-efficacy and satisfaction. British Journal of Educational Technology, 50(3), pp. 1495-1506.

Navimipour, J. and Zareie, B., 2015. A model for assessing the impact of e-learning systems on employees' satisfaction. Computers in Human Behavior, 53 pp. 475-485.

Nguyen, Q., Rienties, B., Toetenel, L,. Ferguson, R., and Whitelock, D., 2017. Examining the designs of computer-based assessment and its impact on student engagement, satisfaction, and pass rates. Computers in Human Behavior., 76 (2017), pp. 703-714.

Nikou, S. A. and Economides, A. A., 2017. Mobile-based assessment: investigating the factors that influence behavioral intention to use. Computers and Education., 109 pp. 56-73.

Obeidallah, R., Ahmad, A.A., Farouq, F., and Awad, S., 2015. Students authentication in e-assessment sessions: a theoretical biometric model for smartphone devices. International Journal of Business Information Systems, 19(4), pp. $450-464$.

Petter, S., DeLone, W. and McLean, E,. 2008. Measuring information systems success: Models, dimensions, measures, and interrelationships. European Journal of Information Systems, 17(3), pp. 236-263.

Pettit, M., Shukla, S., Zhang, J., and Kumar, K. H. S. and Khanduja V., 2021. Virtual exams : has COVID-19 provided the impetus to change assessment methods in medicine ? Bone \& Joint Open [e-journal] 2(2), pp. 111-118.

https://doi.org/10.1302/2633-1462.22.BJO-2020-0142.R1 
Ramayah, T., Ahmad, N. H. and Hong, T. S., 2012. An assessment of e-training effectiveness in multinational companies in Malaysia. Educational Technology and Society, 15(2), pp. 125-137.

Ramayah, T. and Lee, J. W. C., 2012. System characteristics, satisfaction and e-learning usage: a structural equation model (SEM). Turkish Online Journal of Educational Technology, 11(2), pp. 196-206.

Ramayah, T., Nejati, M. and Shafaei, A., 2015. Modelling predictors of blog stickiness and retention by university students. Malaysian Journal of Library and Information Science, 20(3), pp. 15-27.

Ringle, C. M., Wende, S. and Becker, J.-M., 2015. "SmartPLS 3." Boenningstedt: SmartPLS GmbH'. Available at: http://www.smartpls.com. [Accessed 10 January 2020].

Sanni, A. A., and Mohammad, M. F., 2015. Computer based testing ( cbt ): an assessment of student perception of jamb utme in Nigeria. Computing, Information Systems, Development Informatics \& Allied Research Journal, 6(2), pp. 116.

Saya, S., Pee, L. G. and Kankanhalli, A., 2010. The impact of institutional influences on perceived technological characteristics and real options in cloud computing adoption. In: ICIS 2010 Proceedings - Thirty First International Conference on Information Systems. St. Louis. Available at https://aisel.aisnet.org/icis2010_submissions/24/ [accessed on 30 May, 2020]

Seddon, P. B., 1997. A respecification and extension of the Delone and Mclean model of IS success. Information Systems Research, 8(3) pp. 240-253.

Sedera, D. and Gable, G., 2004. A factor and structural equation analysis of the enterprise systems success measurement model. In: Twenty-Fifth International Conference on Information Systems, August 2004. New York.

Seta, H. B., Wati, T., Muliawati, A., and Hidayanto, A.N., 2018. E-learning success model: an extention of Delone and Mclean IS' success model. Indonesian Journal of Electrical Engineering and Informatics, 6(3), pp. 281-291.

Shee, D. and Wang, Y. H., 2008. Multi-criteria evaluation of the web-based e-learning system: a methodology based on learner satisfaction and its applications. Computers \& Education, 50(3), pp. 894-905. doi:10.1016/j.compedu.2006.09.005

Terzis, V. and Economides, A. A., 2011. The acceptance and use of computer based assessment. Computers and Education. 56(4), pp. 1032-1044.

Terzis, V., Moridis, C. N. and Economides, A. A., 2013. Continuance acceptance of computer based assessment through the integration of user's expectations and perceptions. Computers and Education. 62, pp. 50-61. doi: 10.1016/j.compedu.2012.10.018.

Urbach, N. and Ahlemann, F., 2010. Structural equation modeling in information systems research using partial least squares. Journal of Information Technology Theory and Application, 11(2), pp. 5-40.

Vairamuthu, S. and Anouncia, S. M., 2016. Reconnoitering students ' satisfaction of an online based assessment system to improve usability using pso : an examination into a problem solving and programming course. Engineering, Technology \& Applied Science Research, 6(5), pp. 1207-1211.

Wafaa, S,. Mohamed, R., Hossameldin, A., 2021, Effectiveness of e-Assessment in quantitative modules, COVID-19 Consequences: a aase study by the British university in Egypt. In: International Conference on Interactive Collaborative and Blended Learning, 2021, pp 466-477, doi: 10.1007/978-3-030-67209-6_50

Wang, Y. S., 2003. Assessment of learner satisfaction with asynchronous electronic learning systems. Information and Management, 41(1), pp. 75-86.

Wang, Y., So, K. K. F. and Sparks, B. A., 2017. Technology readiness and customer satisfaction with travel technologies: a cross-country investigation. Journal of Travel Research, 56(5), pp. 563-577.

Yakubu, M. N., and Dasuki, S. I., 2018. Assessing elearning systems success in Nigeria: an application of the Delone and Mclean information systems success model. Journal of Information Technology Education: Research, 17, 182-202. https://doi.org/10.28945/4077.

\section{Appendix 1}

\begin{tabular}{|l|l|l|}
\hline Construct & Items & \\
\hline E_assessment cost-effectiveness & CEF1 & I find the overall price of UTME CBT inexpensive. \\
\hline & CEF2 & UTME CBT deserves the current price. \\
\hline & CEF3 & I find UTME CBT cost-effective. \\
\hline Questions Content Quality & QCQ1 & UTME CBT's questions were clear and understandable. \\
\hline & QCQ2 & UTME CBT's questions were relative to the subjects' syllabus. \\
\hline & QCQ3 & UTME CBT's questions were useful for my course \\
\hline E-assessment Satisfaction & SAT1 & UTME CBT is enjoyable. \\
\hline & SAT2 & I am pleased enough with the UTME CBT system. \\
\hline & SAT3 & The UTME CBT system satisfies my examination needs. \\
\hline & SAT4 & I am satisfied with the performance of the UTME CBT system. \\
\hline & SAT5 & UTME CBT was pleasant to me. \\
\hline System Quality & SAT6 & UTME CBT gives me self-confidence. \\
\hline & SYQ1 & The UTME CBT system is easy to use. \\
\hline & SYQ2 & The UTME CBT system is stable. \\
\hline
\end{tabular}


Hassan Bello and Nor Athiyah Abdullah

\begin{tabular}{|l|l|l|}
\hline Construct & Items & \\
\hline & SYQ3 & $\begin{array}{l}\text { The UTME CBT system protects my information from unauthorized } \\
\text { access by logging only with my account and password. }\end{array}$ \\
\hline & SYQ4 & UTME CBT system runs very fast \\
\hline & SYQ5 & The UTME CBT system responds quickly to my request. \\
\hline
\end{tabular}

